\title{
The Application of Mind Mapping in Foreign Language Teaching
}

\author{
Cui Jingjing \\ Jilin Business and Technology College, P.R. China, 130062 \\ 107851252@qq.com
}

\begin{abstract}
In the practice of teaching, the interesting, diversity, flexibility and scientific nature of Mind Mapping are constructed for the students' mind mapping, which is based on the level of psychological development, and can be formed on the basis of intrinsic motivation. It provides the internal conditions for action thinking. This paper explores that the application of mind mapping in FLT and the influence of mind mapping on FLT.
\end{abstract}

Keywords-Mind mapping; Classroom mode, thinking ability

\section{INTRODUCTION}

The famous British scholar Tony Bazin puts forward a note-taking method in 1960s which called mind mapping. Mind mapping is a graphic thinking tool for expressing divergent thinking, and an external manifestation of the "map" of the internal thought of the brain. Mind mapping is an effective and visual thinking tool to express divergent thinking. It can promote the divergence of thinking and record the divergent process, so it is the guidance and record of thinking process. The "classroom" model of mind mapping is to apply the new thinking of Tony Bozan on mind mapping to foreign language teaching. [1]This is a new mode of thinking of strategic transfer of language teaching, but also a thinking activity that students participate in. Students can turn a long list of boring messages into colorful, easy-to-remember and highly organized graphs. To some extent, the more solid accumulation of students' experience to have, the more rapid and positive of the pattern of mind mapping to reflect. The various schemas stored in the memory can help students to activate the existing schema and diverge the meaning of the nodes in the rapid mapping, so that the mind map is more and more natural extension of the way in accordance with the brain thinking. At the same time, it also can help the students to make analysis, synthesis, judgment, reasoning and other cognitive activities on the basis of the appearance and the concept. The use of mind map, the students have a positive role in promoting learning. Therefore, the application of mind mapping in FLT is theoretical and practical significance to the construction of new thinking and mode of English teaching.

\section{MIND MAPPING AND FLT}

Foreign language teaching should eliminate "literacy teaching", which transforms the foreign language teaching into effective teaching. Foreign language teachers should change teaching concepts and teaching mode and improve teaching methods, which involves in stability pursuit changing, changing in reflection and thinking in the improvement. With the deepening of cognitive psychology and pedagogy, the practice of foreign language teaching has been carried out and deepened. The ability of cultivating language ability, thinking ability and learning ability has been put on the agenda. [2]Grammar translation method has been difficult to meet this requirement. And the use of mind mapping in teaching, you can guide the learners meaningful learning in the construction of the autonomy of knowledge to achieve the level of development from the existing level of language awareness to another new higher level of development. The mind mapping provides a good framework for the learners to construct the active meaning of the language knowledge and language learning process. At the same time, it activates the exploratory and mining advanced thinking modes in the process of language learning and encourages the initiative of learning in teaching. Mind mapping can help teachers to organize the course content into a more effective integration framework in teaching process so that learners will make the connections between the new language information and the original concept of cognitive structure. And it also can expand cognitive schema for foreign language teachers. In addition, it is a visual representation of the cognitive structure that can serve as a template to help organize knowledge and structure it. It can help learners organize, store and extract knowledge when they are presented as language knowledge information. In addition, the scaffolding teaching can follow the five links of scaffolding teaching mode of constructivism into the scene, independent thinking, collaborative learning and effect evaluation. This model embodies the initiative, situational and social nature of learning in teaching, which helps learners to more clearly perceive the communicative function of the language. In the process of collaborative learning and constructive meaning, it acquires the ability to use language in a gradual and orderly manner.[3] In short, the scaffolding instructional model of mind mapping will strengthen the connection between semantic knowledge and image knowledge in the whole foreign language teaching process of listening, speaking, reading and writing and promote the cognitive structure of learners to be in the active state. Whereas, it promotes from the old knowledge to the new and from teaching methods to leaning methods which help learners make constructive learning, cumulative learning, collaborative learning and reflective learning, and ultimately realize the real meaningful language learning.

The application of mind mapping in teaching can help students to build the connection between the existing schema and the new schema among the professional disciplines. In 
particular, learners sort out the knowledge learned and then summarized and expressed in the form of keywords. Thus, the line will be showed different concepts, knowledge points or worthy points which is paid attention to. These lines have been linked with each other, which will help inspire the divergence thinking and form students thinking of the dominant and more profound understanding of what they have learned or sentiment. We observed in the application and found that students can think knowledge (Understanding), comprehension (understanding), application (application), analysis (analysis), synthesis (synthesis) and evaluation (evaluation) that have been input the knowledge according to self-experience and knowledge we have been grasped. The process of constructing mind mapping is the language interaction dynamic process through thinking, emotion, imagination. It is the possibility of producing and development for other classroom intelligence activities (learning skills) for students to build their own mind maps and with the gradual improvement of mapping mind. Using mind mapping, students are motivated by intrinsic nature and motivation; are interested in new ideas and new ways of thinking; are able to look at the whole picture and establish connections between concepts, meanings, ideas and their own views.[4] In particular, the horizontal connection between the number of nodes and the number of layers in the mind map evokes the depth of the thought and emotion of the students and the association of the cognitive breadth in the mind. Students transform not only covey the information, but also form deep moral and philosophical values into the developmental thinking and personality of the reading material into thinking ability and cognitive ability so that it can shape the spirit from the inside. Thereby, mind mapping can help students enhance the concept of capacity, deepen the" background knowledge and improve the" processing strategy". Mind mapping is the ultimate organizational thinking tool which shows full of imagery and natural thought process of the human brain.

\section{THE IMPACT OF MIND MAPPING IN FLT}

As a thinking mode of guiding thinking and guiding behavior, mind mapping has played a very important role in foreign language teaching and foreign language learning. It stimulates the learners' enthusiasm for thinking, strengthens the logical thinking; strengthens the logical memory ability; enlarges the thinking divergence; urges the imagination space more greatly, uses the mind map to guide the teacher to carry on the teaching reflection and the innovation and enhances the self-understanding. At the same time, teachers understand the effect of colleagues, a concrete study of teaching theory and professional knowledge of the effective way by mind mapping effectively.

\section{A. The impact of foreign language teachers}

Teachers' routine teaching activities gradually transform into an exploratory teaching action research under the guidance of the teaching strategy of mind mapping. It realize the teaching goal that teachers start from the individual teaching practice in certain specific problems and search and collect information from the real classroom situation. And then foreign language teachers analyze the problem put forward the innovative teaching mode, reflect the teaching method and improve the purpose of individual teaching. The results produced by teaching activities continue to become the teaching practice-oriented reference or the basis for the implementation of goals. In particular, by observing students' mind maps, teachers can quickly determine and detect students' understanding of teaching content and learning content, and adjust efficient and feasible teaching strategies. Self - monitoring, self - evaluation and self - reinforcement are very important for the improvement of teaching and learning quality and students' thinking ability, which are the supervision, guidance and evaluation of students' classroom activities, as well as students' attention to curriculum objectives. From the psychological point of view, thinking is a kind of ability and the ability to make learners more selfdevelopment. From the behavioral point of view, thinking ability is the learning content, process and learning and the external environment. Teachers analyze this problem-solving methods used in foreign language teaching through the promotion of the map of the map structure analysis and create a logical integration and the level of knowledge systems. At the same time, the course of design can be targeted and guided the setting of classroom problems to stimulate the enthusiasm of students to learn, and then improve classroom teaching. Teachers can also guide the integration of teaching content and create the innovative knowledge of memory methods so that students can improve learning capacity and learning efficiency. In this way, teachers can more easily communicate with students and understand the students' thinking patterns, which continue to promote the development of the teaching cause and create a new and efficient education model.

\section{B. The impact of foreign language learners}

Foreign language learners use mind mapping to construct their own thinking process, which can be used in combination with their own actual situation. They can combine their own learning methods and thinking methods with this model to better understand classroom knowledge points. They also can use the mind mapping to build their own unique way of learning and play their own initiative and active learning. Mind mapping is effective tools to improve students' thinking skills which help students develop thinking activities, in particular, and contribute to the development of students' divergent thinking. Mind mapping helps to develop students' divergent thinking. It can be said that the use of mind mapping a kind of innate from the students' mind, instead, monotonous and repetitive way of education inhibited by the release of the potential of thinking. Mind mapping improves the students' cognitive strategies, and promote the formation of divergent thinking ability. Divergent thinking ability is the prerequisite for students to learn on the personal experience, that is, "action thinking in the formation." The "classroom-oriented" teaching model of mind mapping has created the external environment for students to form "action thinking". The interesting, flexible, diversified and scientific nature of mind mapping is also constructed for the students' mind mapping, which is based on the level of psychological development, and can be formed within the motive of internal motivation.[6] Mechanism provides the action thinking in the formation of internal conditions. It can be said that the use of mind mapping makes 
students a kind of innate, but monotonous and repetitive way of education inhibited by the release of the potential of thinking, cognitive strategies and thinking ability in selfexperience to gradually improve and enhance.Cognitive strategies and thinking ability in self-experience can be gradually improved and enhanced. The sense of responsibility in thinking strengthened from student learning objectives gradually holds understanding, learning and special insights and behavior of new information creatively. Therefore, teachers and students can achieve the "multi-objective" through the "classroom-oriented" mind mapping teaching model, maintain the continuous development of personal knowledge and ability, adjust and modify classroom teaching strategies or improve learning habits and scientifically enhance teaching and learning Effect. Mind mapping provides students with an effective knowledge management tool. Students, in the process of mapping the mind map, can be very easy to organize their knowledge structure, improve their practical ability and learning ability, as well as reduce mechanical memory in the processing of information, change learning attitude from passive learning to active learning, thus stimulating their interest in learning. Students can express the correct or wrong understanding of knowledge, draw their knowledge of the situation, and easily find the logical relationship between teaching content [7]. At the same time, students can effectively show the level of understanding of knowledge through the icon, which not only help to improve students' self-confidence, but also help them find the problem, and explore the answers to improve their independent learning, independent solution Problem.

\section{CONCLUSION}

Foreign language learner's thinking ability can be enhanced by mind mapping, in the meantime, and stimulate learner's association and outside the box. It is the most fundamental basis that brain and thinking in the form of language logic is a highly consistent way of thinking. It restores the original thinking of the brain and fundamentally brings about the traditional linear thinking breakthrough. It transfers the language teaching mode of strategic. The mind mapping "classroom - based" teaching model can promote the development of students' divergent thinking ability and the formation of a new teaching and learning strategy. Mind mapping not only can promote teachers' teaching effect, but also can create the foreign language learners' way of thinking. Therefore, mind mapping is the essential part for foreign language teaching. Mind maps are one used for learning and memory of an effective tool. Students must take the initiative to use mind mapping to learn, whether it is hand-drawn mind map or based on computer mapping of the mind map, they have to hands-on practice, only in this way, we can sort out the content of the order, framework, knowledge, joint department, in order to truly appreciate the magical wonders of mind map, and then experience to it to improve learning efficiency and memory of the magical effect.

\section{REFERENCES}

[1] [British] Tony Bozan, Barry Bozan. Ye Gang translation. Mind map [M]. Beijing: CITIC Publishing House, 2009.

[2] Wu Zunmin. Mind mapping and comprehensive English curriculum objectives of the study [J]. China Foreign Language Education, 2008, (1): 8.

[3] Christine Nuttall.Teaching Reading Skills in a Foreign Language [M]. Landon: Heinemann Educational BooksLtd, 1982.

[4] Tony Bazin. Mind Mapping Series - mind mapping brain instruction [M] Translated by Zhang Dingkun and Xu Keru. Beijing: Foreign Language Teaching and Research Press, 2005 (4): 3.

[5] Shen Jianqiang. The theoretical basis of application of mind mapping in teaching [J]. Reform Frontier, 2009 (6): 48.

[6] Wei Xia. "China); Research on the Learning Mode of "Mind Mapping" [J]. Modern Educational Equipment, 2009 (14): 111.

[7] Zhang Xiaohua,Explore On the Application of Mind Mapping in Learning. [J]. Fujian Computer,2007, (7):194-195 